\title{
Disordered eating and the muscular ideal
}

\author{
Scott Griffiths ${ }^{*}$, Stuart B Murray ${ }^{2}$ and Stephen Touyz ${ }^{1}$
}

Keywords: Disordered eating, Muscularity, Male body image, Muscular ideal

Despite sparse scientific attention, research efforts during the past decade have begun to reveal the complexity of male body image concerns. Early research conceptualised and measured male body dissatisfaction in terms of the drive for thinness and excess body fat E.g. [1]. However, most men in Western societies desire a body that combines low body fat with well-developed musculature, and which is further characterised by broad shoulders, a narrow waist, and big biceps [2,3]. The simultaneous pursuit of overt musculature and low body fat has led researchers to conceptualise muscle dissatisfaction and body fat dissatisfaction as separate but related constructs that are equally central to male body image [4]. Recent research has been dedicated to the development of instruments that measure fat- and muscularity-related body image concerns in men, so that the full spectrum of male body dissatisfaction can be assessed [5,6].

However, in contrast to research efforts on body image pathology, little research has attempted to delineate various dimensions of disordered eating as they pertain to the muscular ideal. Current conceptualisations of disordered eating are synonymous with body fat, fat loss, weight loss and calorie restriction, all of which characterise the drive for thinness, not the drive for muscularity. This bias in our understanding of what constitutes disordered eating is evident in the research instruments used to measure disordered eating behaviours. The gold standard Eating Disorders Examination [7] contains mostly thinness-oriented items. For example, "Have you gone for periods of eight or more waking hours without eating anything in order to influence your shape or weight?", "Have you had a strong desire to lose weight" and "Have you wanted your stomach to be empty?" Such items, whilst appropriate for measuring thinnessoriented eating pathology, are insensitive to eating pathology motivated by the desire for greater muscularity.

\footnotetext{
* Correspondence: scottgriffiths@gmail.com

${ }^{1}$ School of Psychology, University of Sydney, Sydney, NSW, Australia

Full list of author information is available at the end of the article
}

The pursuit of muscularity can be characterised by a variety of rule-driven eating behaviours, many of which are antonymic to eating behaviours that are motivated by the desire to lose body fat and become thin. Muscularityoriented disordered eating behaviours include very high levels of protein consumption, severe restriction of nonprotein related dietary components, interrupting important activities to accommodate frequent eating, continued food consumption despite feeling full, eating very frequently (every 2 to 3 hours), liquefying or blending food for easier intake, consuming a large proportion of calories in liquid form, compensatory restriction of carbohydrates or fats due to deviation from one's training regime, and the use of appearance enhancing drugs such as steroids, "testosterone boosters" and other supplements [8,9]. Contemporary conceptualisations of disordered eating do not easily accommodate these muscularity-oriented facets of disordered eating.

The insensitivity of the current conceptualisation of disordered eating may explain why muscle dissatisfaction and the drive for muscularity have not been reliably associated with disordered eating. Studies on straight and gay men have found that body fat dissatisfaction robustly predicts disordered eating, but have found no such association with muscle dissatisfaction [10-13]. Furthermore, perceived pressure to lose weight directly predicts disordered eating amongst French adolescent boys, but not pressure to gain muscle [14]. Little research has examined the association between drive for muscularity and disordered eating amongst women. Rather than conclude that the desire to be bigger and more muscular does not entail disordered eating, the absence of positive findings may be a consequence of measures that simplistically equate disordered eating with fat loss, weight loss and calorie restriction. Instruments that are sensitive to the full spectrum of disordered eating are needed to enable future investigations into whether muscularityoriented disordered eating is associated with distress and disability in the same way as thinness-oriented disordered eating. 
To improve our understanding of disordered eating behaviours, particularly in men, a reconceptualisation of disordered eating may be warranted; one which focuses on the rules that underlie disordered eating, rather than the specific direction of the eating behaviour. For example, consider an individual who desires thinness and eats very infrequently, and another individual who desires increased muscularity and eats often. The underlying rule that makes this behaviour disordered in both individuals is that they eat meals based on time intervals rather than based on feeling hungry. It is apparent that multiple body ideals, from very thin to very muscular, motivate disordered eating. However, the current conceptualisation of disordered eating is concerned only with thinness, weight loss and calorie restriction, making it outdated and in need of reform.

\section{Competing interests}

The authors declare that they have no competing interests.

\section{Authors' contributions}

SG conceived the idea and drafted the manuscript. SM and ST edited the manuscript and made important revisions. All authors read and approved the final manuscript.

\section{Author details}

${ }^{1}$ School of Psychology, University of Sydney, Sydney, NSW, Australia. ${ }^{2}$ Redleaf Practice, 5 Redleaf Ave, Wahroonga, Sydney, NSW, Australia.

Received: 28 November 2012 Accepted: 12 January 2013

Published: 25 April 2013

\section{References}

1. Feingold A, Mazella R: Gender differences in body image are increasing. Psychol Sci 1998, 9(3):190-195.

2. Cohane GH, Pope HG: Body image in boys: a review of the literature. Int $J$ Eat Disord 2001, 29:373-379.

3. Ridgeway RT, Tylka TL: College men's perceptions of ideal body composition and shape. Psychol Men Masculinity 2005, 6(3):209-220

4. Bergeron D, Tylka TL: Support for the uniqueness of body dissatisfaction from drive for muscularity among men. Body Image 2007, 4:288-295.

5. Cafri G, Thompson JK: Measuring male body image: a review of the current methodology. Psychol Men Masculinity 2004, 5(1):18-29.

6. Tylka TL, Bergeron D, Schwartz JP: Development and psychometric evaluation of the Male Body Attitudes Scale (MBAS). Body Image 2005, 2:161-175.

7. Cooper Z, Fairburn C: The Eating Disorder Examination: a semi-structured interview for the assessment of the specific psychopathology of eating disorders. Int J Eat Disord 1987, 6(1):1-8.

8. Mosley PE: Bigorexia: bodybuilding and muscle dysmorphia. Eur Eat Disord Rev 2009, 17:191-198.

9. Murray SB, Rieger E, Hildebrandt T, Karlov L, Russell J, Boon E, Dawson RT, Touyz SW: A comparison of eating, exercise, shape, and weight related symptomatology in males with muscle dysmorphia and anorexia nervosa. Body Image 2012, 9(2):193-200.

10. Blashill AJ: Elements of male body image: prediction of depression, eating pathology and social sensitivity among gay men. Body Image 2010, 7:310-316.

11. Smith AR, Hawkeswood SE, Bodell LP, Joiner TE: Muscularity versus leanness: an examination of body ideals and predictors of disordered eating in heterosexual and gay college students. Body Image 2011, 8:232-236.
12. Tylka TL: Refinement of the tripartite influence model for men: dual body image pathways to body change behaviors. Body Image 2011, 8(3):199-207.

13. Tylka TL, Andorka MJ: Support for an expanded tripartite influence model with gay men. Body Image 2012, 9(1):57-67.

14. Rodgers RF, Ganchou C, Franko DL, Chabrol H: Drive for muscularity and disordered eating among French adolescent boys: a sociocultural model. Body Image 2012, 9:318-323.

doi:10.1186/2050-2974-1-15

Cite this article as: Griffiths et al:: Disordered eating and the muscular ideal. Journal of Eating Disorders 2013 1:15.

\section{Submit your next manuscript to BioMed Central and take full advantage of:}

- Convenient online submission

- Thorough peer review

- No space constraints or color figure charges

- Immediate publication on acceptance

- Inclusion in PubMed, CAS, Scopus and Google Scholar

- Research which is freely available for redistribution 